\title{
Implications of applying widely accepted cholesterol screening and management guidelines to a British adult population: cross sectional study of cardiovascular disease and risk factors
}

\author{
Nigel Unwin, Richard Thomson, Ann Marie O’Byrne, Mike Laker, Heather Armstrong
}

\begin{abstract}
Objective: To compare the implications of four widely used cholesterol screening and treatment guidelines by applying them to a population in the United Kingdom.

Design: Guidelines were applied to population based data from a cross sectional study of cardiovascular disease and risk factors.

Setting: Newcastle upon Tyne, United Kingdom. Subjects: General population sample (predominantly of European origin) of 322 men and 319 women aged 25-64 years.
\end{abstract}

Main outcome measures: Proportions recommended for screening and treatment.

Methods: Criteria from the British Hyperlipidaemia Association, the British Drugs and Therapeutics Bulletin (which used the Sheffield table), the European Atherosclerosis Society, and the American national cholesterol education programme were applied to the population.

Results: Proportions recommended for treatment varied appreciably. Based on the British Drugs and Therapeutics Bulletin guidelines, treatment was recommended for $5.3 \%$ (95\% confidence interval $2.9 \%$ to $7.7 \%$ ) of men and $3.3 \%$ (1.5\% to $5.3 \%$ ) of women, while equivalent respective values were 4.6 (2.3 to 6.9) and 2.8 (1.0 to 4.6) for the British Hyperlipidaemia Association, 23\% (18.4\% to 27.6\%) and $10.6 \%$ (7.3\% to $14.0 \%)$ for the European Atherosclerosis Society, and $37.2 \%$ (31.9\% to $42.5 \%)$ and $22.2 \%$ ( $17.6 \%$ to $26.8 \%)$ for the national cholesterol education programme. Only the British Hyperlipidaemia Association and Drugs and Therapeutics Bulletin guidelines recommend selective screening. Applying British Hyperlipidaemia Association guidelines, from $7.1 \%$ (4.3\% to $9.9 \%$ ) of men in level one to $56.7 \%(51.3 \%$ to $62.1 \%)$ of men in level three, and from $4.4 \%$ (2.1\% to $6.7 \%)$ of women in level one to $54.4 \%$ (48.9\% to $59.9 \%$ ) of women in level three would have been recommended for cholesterol screening. Had the Drugs and Therapeutics Bulletin guidelines been applied, 22.2\% (16.5\% to $27.9 \%$ ) of men and $12.2 \%(8.6 \%$ to $15.8 \%)$ of women would have been screened.

Conclusions: Without evidence based guidelines, there are problems of variation. A consistent approach needs to be developed and agreed across the United Kingdom.

\section{Introduction}

Considerable attention has been focused recently on promoting evidence based practice and the potential of guidelines to inform and support appropriate care and changes in clinical behaviour. ${ }^{1-3}$ Guidelines have been drawn up on the prevention of coronary heart disease -in particular, on the screening and management of patients with lipid disorders. Guidance on the use of statins, based on the Sheffield table, ${ }^{4}$ was recently circulated to all doctors in the United Kingdom. ${ }^{5}$ There are important differences in the recommendations of the major guidelines, however, yet neither these differences nor the implications for clinical practice have been studied.

We have applied data from a population based survey to the different guidelines for a population aged 25-64 years. ${ }^{6}$ We aimed to describe the potential implications of differences in commonly available and widely promoted guidelines produced by the British Hyperlipidaemia Association, ${ }^{7}$ the British Drugs and Therapeutics Bulletin, ${ }^{8}$ the European Atherosclerosis Society, ${ }^{9}$ and the American national cholesterol education program. ${ }^{10}$

\section{Methods \\ Recruitment and data collection}

The data used in this paper are from the Newcastle heart project-a population based study of coronary heart disease, diabetes, and associated risk factors in the general (predominantly of European origin), Chinese, and South Asian populations of Newcastle upon Tyne. ${ }^{6}$ We have used data from the general population for this paper. This was a population based sample from the patient register of the Newcastle Family Health Services Authority, the list of all individuals in Newcastle registered with a general practitioner. We took an age and sex stratified random sample of those aged 25 to 64 years after removing any Chinese sounding names (less than $0.5 \%$ of the sample). ${ }^{11}$

\section{Lipid analyses}

Subjects were recruited to the study between April 1993 and November 1994. After overnight fasting, subjects' height and weight were measured, their body mass index $\left(\mathrm{kg} / \mathrm{m}^{2}\right)$ was computed, and a fasting blood sample was taken. Until May 1994 the lipid analyses were performed on a Cobas Bio centrifugal analyser (Roche Products Ltd, Welwyn Garden City) and after this date a DAX analyser was used (Bayer plc, Basingstoke). Throughout the study period, the laboratory participated in an external quality assurance scheme. This showed no changes in bias (inaccuracy) for cholesterol or high density lipoprotein cholesterol. However, the data for triglycerides confirmed that the DAX data showed a positive bias relative to the Cobas Bio data and therefore results obtained with the DAX were adjusted as previously described. ${ }^{12}$ The low
Editorial by Fahey and pp 1120, 1130, 1134

Departments of Medicine and Epidemiology and Public Health, University of

Newcastle, Medical School, Newcastle NE2 4HH

Nigel Unwin, senior lecturer

Richard Thomson, senior lecturer

Department of Public Health Medicine, County Durham Health Authority, Durham DH1 5XZ

Ann Marie

O'Byrne,

registrar

Department of

Clinical

Biochemistry and

Metabolic Medicine,

University of

Newcastle,

Newcastle upon

Tyne NE2 4HH

Mike Laker,

reader

Department of

Physiology,

University of

Sunderland,

Sunderland

SR1 3SD

Heather Armstrong, student

Correspondence to: Dr Unwin

n.c.unwin@ncl.ac.uk

BMJ 1998;317:1125-30 


\begin{tabular}{|c|c|}
\hline Population to be screened & Population to be treated \\
\hline \multicolumn{2}{|l|}{ British Hyperlipidaemia Association } \\
\hline In order of priority: & Presence of coronary heart disease and LDL cholesterol >3.4 mmol/l \\
\hline Vascular disease & $\begin{array}{l}\text { Presence of } \geqslant 2 \text { out of: diabetes, hypertension }(1)^{\star} \text {, current smoker, or obesity and LDL cholesterol } \\
>5.0 \mathrm{mmol} / /\end{array}$ \\
\hline Family history $(1)^{\star}$ of coronary heart disease & Male sex and LDL cholesterol >6.0 mmol/ \\
\hline $\begin{array}{l}\text { Diabetes, hypertension }(1)^{\star} \text {, current smoker, or } \\
\text { obesity }\end{array}$ & Female sex, postmenopausal, and LDL cholesterol $>6.0 \mathrm{mmol} / \mathrm{l}$ \\
\hline \multicolumn{2}{|l|}{ Drugs and Therapeutics Bulletin } \\
\hline $\begin{array}{l}\text { Vascular disease, or a family history }(1)^{\star} \text { of coronary } \\
\text { heart disease; or }\end{array}$ & Presence of vascular disease and LDL cholesterol $\geqslant 3.4 \mathrm{mmol} / \mathrm{I}$ \\
\hline $\begin{array}{l}\text { Particular combination of age, sex, hypertension }(1)^{\star} \text {, } \\
\text { left ventricular hypertrophy, smoking, and diabetes } \\
\text { from risk table }\end{array}$ & $\begin{array}{l}\text { If no overt vascular disease, decision from table based on combination of age, sex, diabetes, smoking, } \\
\text { hypertension (1)*, left ventricular hypertrophy, and total cholesterol value }\end{array}$ \\
\hline \multicolumn{2}{|l|}{ European Atherosclerosis Association } \\
\hline \multirow[t]{3}{*}{ All } & Presence of vascular disease and total cholesterol $>5 \mathrm{mmo} / /(<6 \mathrm{mmol} / /$ dietary therapy only $)$ \\
\hline & $\begin{array}{l}\text { Coronary heart disease risk }>20 \% \text { over } 10 \text { years (determined by risk chart according to age, sex, smoking } \\
\text { status, blood pressure, and total cholesterol) and total cholesterol }>5 \mathrm{mmol} / /(<7 \mathrm{mmol} / / \text { dietary therapy } \\
\text { only) }\end{array}$ \\
\hline & Coronary heart disease risk $\leqslant 20 \%$ and total cholesterol $>7 \mathrm{mmol} / \mathrm{l}(<8 \mathrm{mmol} / \mathrm{l}$ dietary therapy only) \\
\hline \multicolumn{2}{|l|}{ National cholesterol education programme } \\
\hline \multirow[t]{3}{*}{ All } & Presence of coronary heart disease and LDL cholesterol $\geqslant 2.6 \mathrm{mmol} / \mathrm{I}(<3.4 \mathrm{mmol} / /$ dietary therapy only) \\
\hline & $\begin{array}{l}\text { LDL cholesterol } \geqslant 3.4 \mathrm{mmol} / /(<4.1 \mathrm{mmol} / / \text { dietary therapy only) and presence of } \geqslant 2(3 \text { if HDL cholesterol } \\
\geqslant 1.6 \mathrm{mmol} / /) \text { out of: male, age } \geqslant 45 \text {, diabetes, hypertension }(2)^{\star} \text {, current smoker, postmenopausal female, } \\
\text { family history of coronary heart disease }(2)^{*}, \mathrm{HDL} \text { cholesterol }<0.9 \mathrm{mmol} / /\end{array}$ \\
\hline & LDL cholesterol $\geqslant 4.1 \mathrm{mmol} / /(<4.9 \mathrm{mmol} / /$ dietary therapy only) with $<2$ risk factors \\
\hline
\end{tabular}

$\mathrm{HDL}=$ high density lipoprotein, $\mathrm{LDL}=$ low density lipoprotein.

${ }^{*}$ See table 2 for definitions of the conditions and risk factors. The studies used two definitions-(1) and (2) - for hypertension and family history of coronary heart disease.

density lipoprotein cholesterol concentration was calculated using the Friedewald formula. ${ }^{7}$

\section{Cardiovascular data}

Subjects had two blood pressure measurements. These were made by trained observers using a standard mercury sphygmomanometer with an alternate size cuff. ${ }^{13}$ A 12 lead electrocardiogram was recorded with the subjects at rest. The findings were coded according to the Minnesota manual by two independent observers; a third observer was used where the two disagreed. ${ }^{14}$ Each subject completed a questionnaire, which included items on diabetes, hypertension, coronary heart disease, and stroke (all diagnosed by a doctor); smoking status; causes of death in any parents or siblings who had died; and the World Health Organisation questionnaire on intermittent claudication. ${ }^{15}$ For women, the questionnaire also inquired about age at the time of the menopause, and any factors affecting its onset. Local ethical committee approval was received for the study and all subjects gave informed consent before participating.

\section{Applying the guidelines}

Space does not permit a detailed description of the guidelines. Here, we have focused on the people for whom the guidelines recommend intensive treatment in the form of rigorous dietary intervention under-

Table 2 Definition of conditions and risk factors used in applying the data to the guidelines

\begin{tabular}{|c|c|c|c|c|c|}
\hline \multirow[b]{2}{*}{ Condition or risk factor } & \multirow[b]{2}{*}{ Definition } & \multicolumn{4}{|c|}{ Included in guideline } \\
\hline & & $\begin{array}{l}\text { British } \\
\text { Hyperlipidaemia } \\
\text { Association }\end{array}$ & $\begin{array}{l}\text { Drugs and } \\
\text { Therapeutics } \\
\text { Bulletin }\end{array}$ & $\begin{array}{l}\text { European } \\
\text { Atherosclerosis } \\
\text { Association }\end{array}$ & $\begin{array}{l}\text { National cholesterol } \\
\text { education } \\
\text { programme }\end{array}$ \\
\hline Diabetes & Reported doctor diagnosis of diabetes & Yes & Yes & Yes & Yes \\
\hline Hypertension (1) & $\begin{array}{l}\text { Blood pressure } \geqslant 160 \text { systolic or } \geqslant 95 \text { diastolic or } \\
\text { receiving medication }\end{array}$ & Yes & Yes & - & - \\
\hline Hypertension (2) & $\begin{array}{l}\text { Blood pressure } \geqslant 140 \text { systolic or } \geqslant 90 \text { diastolic or } \\
\text { receiving medication }\end{array}$ & - & - & - & Yes \\
\hline Current smoker & Self reported current smoker & Yes & Yes & Yes & Yes \\
\hline Obesity & Body mass index $\geqslant 30 \mathrm{~kg} / \mathrm{m}^{2}$ & Yes & - & - & - \\
\hline Vascular disease & $\begin{array}{l}\text { Reported doctor diagnosis of stroke, angina, } \\
\text { myocardial infarction or heart failure, or positive } \\
\text { on WHO intermittent claudication questionnaire }\end{array}$ & Yes & Yes & Yes & - \\
\hline Coronary heart disease & $\begin{array}{l}\text { Reported diagnosis of angina or myocardial } \\
\text { infarction }\end{array}$ & Yes & - & - & Yes \\
\hline Left ventricular hypertrophy & $\begin{array}{l}\text { Minnesota codes 3-1 and 3-3 on resting } 12 \text { lead } \\
\text { electrocardiogram and hypertension (1) }\end{array}$ & - & Yes & - & - \\
\hline Postmenopausal & Self reported cessation of periods & Yes & & & Yes \\
\hline $\begin{array}{l}\text { Family history (1) of } \\
\text { coronary heart disease }\end{array}$ & $\begin{array}{l}\text { Death from coronary heart disease in parent or in } \\
\text { sibling aged } \leqslant 60\end{array}$ & Yes & Yes & - & - \\
\hline $\begin{array}{l}\text { Family history (2) of } \\
\text { coronary heart disease }\end{array}$ & $\begin{array}{l}\text { Death from coronary heart disease in father or } \\
\text { male sibling aged } \leqslant 55 \text { or in mother or female } \\
\text { sibling aged } \leqslant 65\end{array}$ & - & - & - & Yes \\
\hline
\end{tabular}


Table 3 Prevalence of risk factors and coronary heart disease in the study population. Percentages for 25-64 years are directly age standardised to 1991 population of England and Wales

\begin{tabular}{|c|c|c|c|c|c|c|c|c|c|c|c|c|}
\hline \multirow{3}{*}{$\begin{array}{l}\text { Condition or } \\
\text { risk factor* }\end{array}$} & \multicolumn{6}{|c|}{ Men } & \multicolumn{6}{|c|}{ Women } \\
\hline & \multicolumn{2}{|r|}{ Age 25-44 (n=128) } & \multicolumn{2}{|r|}{ Age 45-64 (n=194) } & \multicolumn{2}{|r|}{ Age $25-64$ (n=322) } & \multicolumn{2}{|c|}{ Age 25-44 (n=112) } & \multicolumn{2}{|r|}{ Age 45-64 (n=207) } & \multicolumn{2}{|r|}{ Age 25-64 (n=319) } \\
\hline & No & $\%(95 \% \mathrm{Cl})$ & No & $\%(95 \% \mathrm{CI})$ & No & $\%(95 \% \mathrm{CI})$ & No & $\%(95 \% \mathrm{CI})$ & No & $\%(95 \% \mathrm{Cl})$ & No & $\%(95 \% \mathrm{Cl})$ \\
\hline Diabetes & 0 & & 8 & $4.4(0.5$ to 7.3$)$ & 8 & $1.9(0.7$ to 4.0$)$ & 3 & $2.7(0.6$ to 7.6$)$ & 5 & $2.4(0.7$ to 5.6$)$ & 8 & $2.6(0.9$ to 4.3$)$ \\
\hline Hypertension (1) & 11 & 8.6 (3.7 to 13.5$)$ & 51 & 26.3 (20.1 to 32.5 ) & 62 & 15.4 (11.5 to 19.3$)$ & 2 & $1.8(0.2$ to 6.3$)$ & 36 & 17.4 (12.2 to 22.6$)$ & 38 & 7.8 (4.9 to 10.7$)$ \\
\hline Hypertension (2) & 21 & 16.4 (10.0 to 22.8$)$ & 84 & 43.3 (36.3 to 50.3 ) & 105 & 26.4 (21.6 to 31.2 ) & 3 & $2.7(0.5$ to 7.6$)$ & 58 & 28.0 (21.9 to 34.1$)$ & 61 & 12.2 (8.6 to 15.8 ) \\
\hline Current smoker & 48 & 37.5 (29.1 to 45.9 ) & 61 & 31.9 (25.3 to 38.5$)$ & 109 & 34.8 (29.6 to 40.0$)$ & 39 & 34.8 (26.0 to 43.6$)$ & 53 & 25.7 (19.7 to 31.7) & 92 & 32.2 (27.1 to 37.3 ) \\
\hline Obesity & 18 & 14.1 (8.1 to 20.1) & 30 & 15.5 (10.0 to 21.0$)$ & 48 & 14.5 (10.7 to 18.3$)$ & 14 & 12.5 (6.4 to 18.6$)$ & 49 & 23.8 (18.0 to 29.6 ) & 63 & 16.3 (12.2 to 20.4$)$ \\
\hline $\begin{array}{l}\text { Coronary heart } \\
\text { disease }\end{array}$ & 2 & $1.6(0.2$ to 5.5$)$ & 27 & 13.9 (9.0 to 18.8$)$ & 29 & 6.1 (3.5 to 8.7 ) & 0 & & 15 & $7.2(3.7$ to 10.7$)$ & 15 & 2.7 (0.9 to 4.5$)$ \\
\hline $\begin{array}{l}\text { Left ventricular } \\
\text { hypertrophy }\end{array}$ & 4 & 3.1 (0.8 to 7.8$)$ & 7 & 3.6 (1.6 to 5.8 ) & 11 & 3.7 (1.6 to 5.8$)$ & 0 & & 6 & 2.9 (0.6 to 5.2$)$ & 6 & 1.3 (0.3 to 3.2 ) \\
\hline Postmenopausal & - & & - & & - & & 11 & 10.5 (4.8 to 16.2 ) & 142 & 70.3 (64.1 to 76.5$)$ & 153 & 33.6 (28.4 to 38.8$)$ \\
\hline $\begin{array}{l}\text { Family history } \\
\text { (1) of } \\
\text { coronary heart } \\
\text { disease }\end{array}$ & 11 & 8.6 (3.7 to 13.5$)$ & 10 & 5.2 (2.1 to 8.3$)$ & 21 & 7.1 (4.3 to 9.9 ) & 6 & 5.4 (1.2 to 9.6$)$ & 22 & 10.6 (6.4 to 14.8$)$ & 28 & 7.4 (4.5 to 10.3$)$ \\
\hline $\begin{array}{l}\text { Family history } \\
\text { (2) of } \\
\text { coronary heart } \\
\text { disease }\end{array}$ & 6 & $4.7(1.0$ to 8.4$)$ & 12 & 6.2 (2.8 to 9.6$)$ & 18 & $5.4(2.9$ to 7.9$)$ & 5 & $4.5(1.5$ to 10.1$)$ & 20 & 9.7 (5.7 to 13.7$)$ & 25 & 6.5 (3.8 to 9.2$)$ \\
\hline
\end{tabular}

See table 2 for definitions of the conditions and risk factors.

pinned by professional dietetic advice, with or without drug treatment. Table 1 summarises how we applied each of the guidelines to the data. The European Atherosclerosis Society and national cholesterol education program guidelines specify two target levels for active intervention: one for drug treatment (if a trial of dietary intervention fails) and the other for intensive dietary intervention only. Table 2 gives the definitions of the different conditions and risk factors we used in applying the guidelines to the study population.

\section{Data analysis}

Data were analysed using SPSS software. Results are presented for 20 year age groups and for all ages (25-64 years) for men and women separately. The results for all ages were age adjusted to the 1991 England and Wales male and female populations respectively. Confidence intervals were calculated using Confidence Interval Analysis software (BMJ Publishing, London).

\section{Results}

Altogether 322 men and 319 women aged 25-64 were screened, giving a response rate of $67 \%$. Most subjects were European; 10 men and four women had South Asian sounding names. ${ }^{11}$ Table 3 shows the percent- ages of men and women with the risk factors and conditions used in the analyses. The age adjusted total cholesterol concentrations were mean (SD) 5.6 (1.1) $\mathrm{mmol} / \mathrm{l}$ in men and 5.4 (1.2) in women; the mean high density lipoprotein cholesterol concentrations were 1.3 (0.4) $\mathrm{mmol} / \mathrm{l}$ and $1.6(0.4)$ respectively; and the mean low density lipoprotein cholesterol concentrations were $3.4(1.1) \mathrm{mmol} / \mathrm{l}$ and 3.2 (1.0) respectively.

Table 4 shows the proportions of men and women who would be screened for cholesterol concentration if the guidelines of the British Hyperlipidaemia Association and the Drugs and Therapeutics Bulletin were followed. The proportions vary widely from $4.4 \%$ in women of all ages on the first level of the British Hyperlipidaemia Association guidelines to over 50\% for both men and women on the third level.

Table 5 shows the percentages of men and women recommended for treatment according to the different guidelines. In both men and women, the highest percentages recommended for treatment are associated with the national cholesterol education program guidelines. Here $37 \%$ of men and $22 \%$ of women met the criteria for active intervention, approximately evenly divided between those who would be recommended for intensive dietary treatment only and those who would be recommended for drug treatment if

Table 4 Proportions recommended for cholesterol screening* according to the British Hyperlipidaemia Association and Drugs and Therapeutics Bulletin guidelines. Percentages for 25-64 years are directly age standardised to 1991 population of England and Wales

\begin{tabular}{|c|c|c|c|c|c|c|c|c|c|c|c|c|}
\hline & \multicolumn{6}{|c|}{ Men } & \multicolumn{6}{|c|}{ Women } \\
\hline & \multicolumn{2}{|r|}{ Age $25-44(n=128)$} & \multicolumn{2}{|c|}{ Age $45-64(n=194)$} & \multicolumn{2}{|c|}{ Age 25-64 (n=322) } & \multicolumn{2}{|r|}{ Age 25-44 (n=112) } & \multicolumn{2}{|c|}{ Age 45-64 (n=207) } & \multicolumn{2}{|r|}{ Age $25-64(n=319)$} \\
\hline & No & $\%(95 \% \mathrm{Cl})$ & No & $\%(95 \% \mathrm{CI})$ & No & $\%(95 \% \mathrm{Cl})$ & No & $\%(95 \% \mathrm{CI})$ & No & $\%(95 \% \mathrm{Cl})$ & No & $\%(95 \% \mathrm{CI})$ \\
\hline \multicolumn{13}{|c|}{ British Hyperlipidaemia Association: } \\
\hline $\begin{array}{l}\text { First screening } \\
\text { level }\end{array}$ & 2 & $1.6(0.2$ to 5.5$)$ & 31 & 16.0 (10.8 to 21.2$)$ & 33 & $7.1(4.3$ to 9.9$)$ & 1 & $0.9(0.0$ to 4.9$)$ & 22 & $10.6(6.4$ to 14.8$)$ & 23 & 4.4 (2.1 to 6.7$)$ \\
\hline $\begin{array}{l}\text { Second } \\
\text { screening level }\end{array}$ & 13 & $10.2(5.0$ to 15.4$)$ & 37 & 19.1 (13.6 to 24.6$)$ & 50 & $13.2(9.5$ to 16.9$)$ & 7 & $6.3(1.8$ to 10.8$)$ & 40 & 19.3 (13.9 to 24.7$)$ & 47 & 11.1 (7.7 to 14.5$)$ \\
\hline $\begin{array}{l}\text { Third screening } \\
\text { level }\end{array}$ & 69 & 53.9 (45.3 to 62.5$)$ & 123 & 63.4 (56.6 to 70.2$)$ & 192 & 56.7 (51.3 to 62.1$)$ & 55 & 49.1 (39.8 to 58.4$)$ & 128 & 61.8 (55.2 to 68.4$)$ & 183 & 54.4 (48.9 to 59.9$)$ \\
\hline $\begin{array}{l}\text { Drugs and } \\
\text { Therapeutics } \\
\text { Bulletin }\end{array}$ & 14 & 10.9 (5.5 to 16.3$)$ & 82 & 42.3 (34.3 to 48.1$)$ & 96 & 22.2 (17.7 to 26.7 ) & 7 & 6.3 (1.8 to 10.8$)$ & 46 & 22.2 (16.5 to 27.9 ) & 53 & 12.2 (8.6 to 15.8 ) \\
\hline
\end{tabular}


Table 5 Proportions recommended for active lipid lowering treatment by the different guidelines. Percentages for 25-64 years are directly age standardised to 1991 population of England and Wales

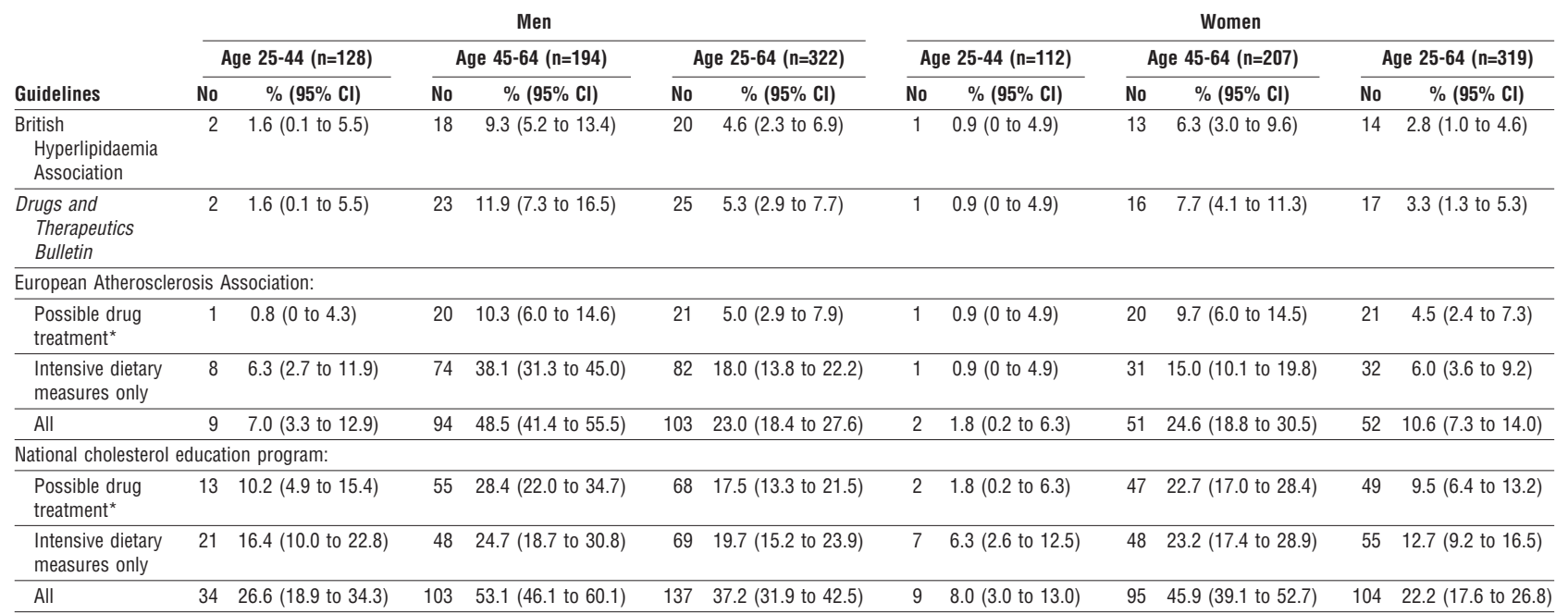

${ }^{*}$ If intensive dietary measures fail to lower cholesterol to target values.

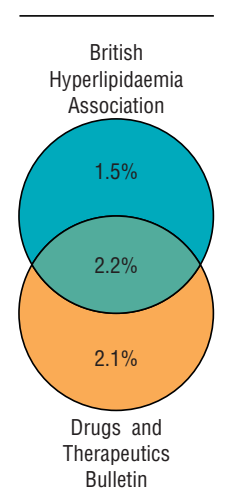

Proportions of men and women aged 25-64 years recommended for active intervention by guidelines from the British Hyperlipidaemia Association and the Drugs and Therapeutics Bulletin dietary measures failed to achieve target levels. The British Hyperlipidaemia Association guidelines produced the lowest percentages recommended for treatment (initially intensive dietary measures with drug treatment if target levels were not reached). These were $4.6 \%$ of men and $2.8 \%$ of women. Although the percentages recommended for treatment by the British Hyperlipidaemia Association and Drugs and Therapeutics Bulletin were similar, the individuals who would have been treated often differed (see figure). Only $2.2 \%$ of the population were recommended for active intervention by both guidelines; an additional $2.1 \%$ were recommended by the Drugs and Therapeutics Bulletin guidelines only and $1.5 \%$ by the British Hyperlipidaemia Association only.

The figures for the British Hyperlipidaemia Association guidelines in table 5 apply to the whole population-that is, irrespective of whether the individuals met the criteria for screening by these guidelines. The figures are lower if they are based only on those individuals who meet both the screening and treatment criteria. Thus, the percentage of men and women who met level one screening criteria and treatment criteria were $2.7 \%$ and $1.4 \%$ respectively, while proportions for level two were $3.0 \%$ and $1.4 \%$ and those for level three were $3.7 \%$ and $2.4 \%$. For the men and women together, the sensitivity (those defined as needing treatment who would be screened divided by all those needing treatment) for screening level three was $83.3 \%$, and the specificity (those defined as not needing treatment who would not be screened, divided by all those not needing treatment) was $45.5 \%$. The criteria for screening and treatment for the Drugs and Therapeutics Bulletin are such that all those who meet the criteria for treatment also meet the criteria for screening, giving, by default, a sensitivity of $100 \%$. The specificity was $86.6 \%$ for men and women together.

\section{Discussion}

Strengths and weakness

This paper aimed to describe the differing implications of commonly available and widely promoted British
(British Hyperlipidaemia Association, Drugs and Therapeutics Bulletin), European (European Atherosclerosis Society), and American (national cholesterol education program) guidelines for the management of hyperlipidaemia. To apply the guidelines to our data we needed to make several assumptions, sometimes because of the vagueness of the guidelines and sometimes because of the limitations of our data. These included, for example, basing "a strong family history of premature coronary disease" on reported death from coronary heart disease in a first degree relative, as we did not have data on non-fatal events in relatives.

Three of the four guidelines considered state explicitly that treatment decisions should be based on more than one cholesterol measurement. Our data are based on a single fasting measurement, and, undoubtedly, repeat measurements on subjects whose initial concentrations had been high would have reduced the numbers recommended for treatment.

In addition, our data are from a population based survey with a response rate of $67 \%$. This survey may have underestimated the prevalence of coronary heart disease and some risk factors. For example, in the health survey of England, those subjects who consented to a blood test had a lower mean systolic blood pressure and lower prevalences of smoking and coronary heart disease. ${ }^{16}$ Comparing our data, in 10 year age groups, to those from the health survey of England suggests that the prevalences of smoking, obesity, and hypertension (defined as $\geqslant 160 /$ $95 \mathrm{~mm} \mathrm{Hg}$ or taking antihypertensive treatment) in men are similar to those for England as a whole in 1993/94. ${ }^{17}$ The prevalence of hypertension in women in our sample is around half that found in the health survey. However, the data we used here are broad and have enabled us to apply most criteria from the different guidelines. Thus, although we cannot claim that our results reflect accurately the proportion of the population who require treatment in a clinical context, we are confident that they do reflect reasonably the relative differences between the guidelines for screen- 
ing and treatment, and this was the primary purpose of this study.

\section{Implications of the findings}

There were wide differences between the implications of some of the guidelines. The highest proportions of men $(37 \%)$ and women $(22 \%)$ came within the treatment category where the national cholesterol education program guidelines were applied. The proportions of men and women recommended for treatment by the guidelines of the British Hyperlipidaemia Association and Drugs and Therapeutics Bulletin were similar-men $4.6 \%$ compared with $5.3 \%$ and women 2.8\% compared with $3.3 \%$ respectively. However, the individuals who would have been treated differed (figure).Thus, it is not simply that some guidelines suggest more aggressive intervention but also that they advise treatment for different subgroups. It is also clear that even the most liberal screening criteria recommended by the British Hyperlipidaemia Association (level three in table 1) would not identify all patients recommended for treatment by those guidelines.

Balancing considerations of sensitivity and specificity is a common problem in defining screening criteria. In this context it is worth noting that the recent Effective Health Care bulletin on cholesterol and coronary heart disease comes down firmly against universal cholesterol screening. ${ }^{18}$ It also argued cogently that guidance must be based on the assessment and management of overall cardiovascular risk and not just one aspect, such as the cholesterol concentration.

A questionnaire survey of health authorities or boards in the United Kingdom in 1994 found considerable variation and inconsistency in local criteria for cholesterol testing and treatment. ${ }^{19}$ Our local experience suggests there is much heterogeneity-guidelines of the British Hyperlipidaemia Association, European Atherosclerosis Society, and criteria based on the Sheffield table were used, and, most recently, guidance has been issued from the Standing Medical Advisory Committee based on the Sheffield table. ${ }^{5}$ The implication is that there are considerable inconsistencies in the management of hyperlipidaemia within the United Kingdom. It has been previously observed that locally produced guidelines for the use of anticoagulants in atrial fibrillation and widely used hypertension guidelines also differ greatly in their implications for numbers treated. ${ }^{20} 21$

\section{Clear guidance needed}

The need for consistent clear guidance on screening for and management of hyperlipidaemia is ever more pressing as evidence of the effectiveness of newer but expensive agents, the statins, accumulates. ${ }^{22-24}$ Unfortunately, recent guidance issued to all doctors in the United Kingdom ${ }^{5}$ falls short of what is required-it considers only drug management, fails to present the evidence, and ignores issues of cost effectiveness. ${ }^{25}$ It adds to the confusing array of guidelines illustrated in this paper rather than helping to identify and resolve the reasons for differences between them.

The major lipid management guidelines published to date have depended upon consensus development processes and not on the systematic evidence linked review of published reports that is now recognised as a
Key messages

- Several widely available guidelines give different advice for managing hyperlipidaemia

- Proportions of the population deemed eligible for screening and treatment can differ considerably between guidelines

- Even when the proportions eligible for treatment are similar, the individuals often differ

- There are probably inconsistences in the management of hyperlipidaemia in the United Kingdom

- Explicitly derived, scientifically valid guidelines that include a consideration of costs are urgently needed

necessary part of the process of developing scientifically valid guidelines. ${ }^{26}{ }^{27}$ Furthermore, none of the guidelines have addressed the economic and service consequences of their application as part of their development process. The need for explicitly derived, scientifically valid guidelines that include a consideration of costs is clear.

Contributors: NU had the original idea for the study, and developed it with RT and ML. AMO'B reviewed and summarised the guidelines, helped by HA. NU was responsible for data analysis, assisted by AMO'B and HA. HA undertook a detailed literature review and collated the tables. NU was responsible for the writing and revision of the paper, assisted particularly by RT, but with contributions from all the others. ML was responsible for the lipid analyses.

Professors George Alberti and Raj Bhopal, Dr Martin White, Bill Watson, and Jane Harland were all part of the team who designed and managed the data collection for the Newcastle Heart Project. Dr Peter Stephenson, Sisters Margaret Miller, Catherine Turner and Mavis Brown, and nurse Amanda McEwan helped with data collection, assisted at times by Dr Dalip Singh. We thank N Keen for ECG coding and Martin White, Julie Yallop, and Jane Harland for commenting on a draft of this paper.

Funding: Newcastle and North Tyneside Health Authority, Barclay Trust, and British Diabetic Association.

Conflict of interest: None.

1 NHS Centre for Reviews and Dissemination. Implementing clinical practice guidelines. Effective Health Care 1994;4(1).

2 Grimshaw J, Russell I. Effect of clinical guidelines on medical practice: A systematic review of rigorous evaluations. Lancet 1993;342:1317-22.

3 Thomson RG, Lavender M, Madhok R. How to ensure that guidelines are effective. BMJ 1995;311:237-42.

4 Ramsay L, Haq I, Jackson P, Yeo W. The Sheffield table for primary prevention of coronary heart disease: corrected. Lancet 1996;348:1251-2.

5 Standing Medical Advisory Committee. The use of statins. London: Standing Medical Advisory Committee, 1997.

6 Unwin N, Harland J, White M, Bhopal R, Winocour P, Watson W, et al. Body mass index, waist-hip ratio and glucose intolerance in Chinese and European adults. J Epidemiol Community Health 1997;51:160-6.

7 Betteridge D, Dodson P, Durrington P, Hughes E, Laker M, Nicholls D, et al. Management of hyperlipidaemia: guidelines of the British Hyperlipidaemia Association. Postgrad Med J 1993;69:359-69.

8 Management of Hyperlipidaemia. Drug Therap Bull 1996:34:89-93.

9 Pyorala K, Backer GD, Graham I, Poole-Wilson P, Wood D, on behalf of the task force. Prevention of coronary heart disease in clinical practice: recommendations of the task force of the European Society of Cardiology, European Atherosclerosis Society and European Society of Hypertension. Eur Heart J 1994;15:1300-31.

10 National Cholesterol Education Programme. Second report of the expert panel on detection, evaluation, and treatment of high blood cholesterol in adults (Adult treatment panel 2). Circulation 1994;89:1333-45.

11 Coldman AJ, Braun T, Gallagher RP. The classification of ethnic statu using name information. J Epidemiol Community Health 1988;42:390-5.

12 Harland JO, Unwin N, Bhopal RS, White M, Watson W, Laker M, et al. Low levels of cardiovascular risk factors and coronary heart disease in a UK Chinese population. J Epidemiol Community Health 1997;51:636-42. 
13 Petrie JC, O'Brien ET, Littler WA, Swiet MD, Dillon MJ, Padfield PL. Recommendations on blood pressure measurements. 2nd ed. London: BMJ Publishing Group, 1990.

14 Prineas R, Crow R, Blackburn H. The Minnesota code manual of electrocardiographic findings. London: John Wright, 1982.

15 Rose G, Blackburn A, Gillum R, Prineas R. Cardiovascular survey methods. 2nd ed. Geneva: World Health Organisation, 1982.

16 Bennett N, Dodd T, Flatley J, Freeth S, Boiling K, for the Office of Population Censuses and Surveys. Health survey for England 1993. London: HMSO, 1995

17 Department of Health. Health survey for England '96. London: Stationery Office, 1998.

18 NHS Centre for Reviews and Dissemination. Cholesterol and coronary heart disease: screening and treatment. Effective Health Care 1998; No 4.

19 Raine R, Streetly A, Davis AM. Variation in local policies and guidelines for cholesterol management: national survey. BMJ 1996;313:1368-9.

20 Thomson R, McElroy H, Sudlow M. Guidelines on anticoagulant treatment in atrial fibrillation in Great Britain: variation in content and implications for treatment. BMJ 1998;316:509-13.

21 Fahey TP, Peters TJ. What constitutes controlled hypertension? Patient based comparison of hypertension guidelines. BMJ 1996;313:93-6.
22 Pedersen TR, Kjekshus J, Berg K, Haghfelt T, Faergeman O, Thorgeirsson $\mathrm{G}$, et al. Randomised trial of cholesterol lowering in 4444 patients with coronary heart disease: the Scandinavian simvastatin survival study (4S). Lancet 1994;344:1383-9.

23 Sacks FM, Pfeffer MA, Moye LA, Rouleau JL, Rutherford JD, Cole TG, et al. The effect of pravastatin on coronary events after myocardial infarction in patients with average cholesterol levels. $N$ Engl J Med infarction in pation:

24 Shepherd J, Cobbe SM, Ford I, Isles CG, Lorimer AR, Macfarlane PW, et al. Prevention of coronary heart disease with pravastatin in men with hypercholesterolemia. N Engl J Med 1995;333:1301-7.

25 Freemantle N, Barbour R, Johnson R, Marchment M, Kennedy A. The use of statins: a case of misleading priorities? National guidance that does not link costs and benefits is worthless. BMJ 1997;315:826-8.

26 Grimshaw J, Russell I. Achieving health gain through clinical guidelines I: Developing scientifically valid guidelines. Qual Health Care 1993;2:243-8.

27 Eccles M, Clapp Z, Grimshaw J, Adams PC, Higgins B, Purves I, et al. North of England evidence based guidelines development project: methods of guideline development. BMJ 1996;312:760-1.

(Accepted 6 July 1998)

\title{
From trial data to practical knowledge: qualitative study of how general practitioners have accessed and used evidence about statin drugs in their management of hypercholesterolaemia
}

\author{
Karen Fairhurst, Guro Huby
}

Editorial by Fahey and $p p 1120,1125$, 1134

Department of Community Health Sciences (General

Practice), University of Edinburgh, Levinson House, Edinburgh EH8 9DX

Karen Fairhurst, lecturer

Guro Huby, research associate

Correspondence to: Dr Fairhurst Karen.Fairhurst@ ed.ac.uk

BMJ 1998;317:1130-4

\begin{abstract}
Objectives To explore how general practitioners have accessed and evaluated evidence from trials on the use of statin lipid lowering drugs and incorporated this evidence into their practice. To draw out the practical implications of this study for strategies to integrate clinical evidence into general medical practice.
\end{abstract}

Design Qualitative analysis of semistructured interviews.

Setting General practices in Lothian.

Subjects 24 general practitioners selected to obtain a heterogeneous sample.

Results Respondents were generally aware of the evidence relating to the use of statins in secondary prevention of coronary heart disease, but they were less clear about the evidence in primary prevention. The benefits of statins in secondary prevention were clearer to them and the social and economic issues less complex than was the case for use in primary prevention. Respondents rarely said they appraised the methods and content of trials, rather they judged the trustworthiness of the source of trial evidence and interpreted it within the context of the economic and social factors which impinge on their practice.

Moreover, trial data become relevant for routine practice only when underpinned by a consensus on these issues.

Conclusion Strategies to promote incorporation of evidence from clinical trials into everyday practice are likely to be effective if they tap into and build on the process of local consensus building. Strategies such as teaching critical appraisal skills and guideline development may have little effect if they are separated from this process.

\section{Introduction}

Use of evidence from clinical trials to underpin routine practice is seen as a key part of achieving a cost effective health service that offers consistent high quality care. ${ }^{12}$ Evidence based medicine requires doctors to appraise clinical trials critically to determine the best way of managing a patient's clinical problem. ${ }^{3}$ Evidence based medicine is seen as particularly problematic in general practice, where clinical problems are presented in complex social and psychological contexts. ${ }^{4}$ Although support for the principle of evidence based medicine has been identified among general practitioners, ${ }^{5}$ recognised barriers exist to its implementation. Studies that have explored how general practitioners access evidence and translate this into practice suggest that strategies based on critical appraisal might fail because they are based on unrealistic models of how "evidence" is accessed and evaluated. ${ }^{6-8}$

We present findings from a study in which general practitioners reflected on how they access and incorporate into their practice evidence on management of lipid disorders. We chose this subject as data from recent randomised controlled trials, in particular from the Scandinavian simvastatin survival study $(4 S)^{9}$ and the West of Scotland coronary prevention study (WOSCOPS), ${ }^{10}$ have a high profile and direct relevance to primary care, and local prescribing data suggest wide variation between practices in levels of prescribing of statin drugs. We compared general practitioners' accounts of their current practice with results from the two studies. The Scandinavian study produced evidence of around a $30 \%$ reduction in risk of myocardial infarction and death in patients with known ischaemic heart disease whose total serum cholesterol 